\title{
Summer Convective Afternoon Rainfall Simulation and Projection Using WRF Driven by Global Climate Model. Part II: Over South China and Luzon
}

\author{
Wan-Ru Huang ${ }^{1, *}$, Ya-Hui Chang ${ }^{1}$, Huang-Hsiung $\mathrm{Hsu}^{2}$, Chao-Tzuen Cheng ${ }^{3}$, and Chia-Ying $\mathrm{Tu}^{2}$ \\ ${ }^{1}$ Department of Earth Sciences, National Taiwan Normal University, Taipei City, Taiwan, R.O.C. \\ ${ }^{2}$ Research Center for Environmental Changes, Academia Sinica, Taipei City, Taiwan, R.O.C. \\ ${ }^{3}$ National Sciences and Technology Center for Disaster Reduction, New Taipei City, Taiwan, R.O.C.
}

Received 22 May 2015, revised 20 March 2016, accepted 2 May 2016

\begin{abstract}
This study is the second of a two-part investigation into summer convective afternoon rainfall (CAR) simulation and projection over the East Asian continents. In Part I, we examined the CAR activity over Taiwan. In this study we focus on CAR activity over South China and Luzon using the WRF (Weather Research and Forecasting Model) driven by HiRAM (High Resolution Atmospheric Model) (i.e., WRF-HiRAM). These examinations focus on two time-sliced simulations assuming the climate conditions at present (1979 - 2003, historical run) and at the end of the $21^{\text {st }}$ century (2075 - 2099, RCP 8.5 scenario). The results show that WRF-HiRAM is capable of simulating the spatial-temporal variation in CAR activity over South China and Luzon close to the recorded observations. In the future projections, WRF-HiRAM predicts that CAR events over most of South China and eastern Luzon will become fewer but stronger. Conversely, CAR events over western Luzon will become more frequent and stronger. Analyses also indicate that the projected change in CAR amount over most of South China (except for the coastal regions) and Luzon will be dominated by the change in CAR rate, not the change in CAR frequency. As for the cause of change in CAR rate, WRF-HiRAM projects that atmospheric humidity over South China and Luzon will increase significantly in the future. This will lead to an increase in local CAR rate. In contrast, the projected change in CAR frequency over South China and Luzon is suggested to be greatly modulated by the change in daytime surface wind convergence and thermal instability. Examinations were also performed to document the characteristics and causes of the projected change in CAR activity extracted from HiRAM.
\end{abstract}

Key words: Dynamical downscaling simulations, Local rainfall, South China and Luzon

Citation: Huang, W. R., Y. H. Chang, H. H. Hsu, C. T. Cheng, and C. Y. Tu, 2016: Summer convective afternoon rainfall simulation and projection using WRF driven by global climate model. Part II: Over South China and Luzon. Terr. Atmos. Ocean. Sci., 27, 673-685, doi: 10.3319/TAO.2016.05.02.02

\section{INTRODUCTION}

During summer (June, July, and August, or JJA), the precipitation over the East Asian region exhibits a clear seasonal variation and also shows conspicuous diurnal variability (Zhao et al. 2005; Dai et al. 2007; Yu et al. 2007a, b; Kikuchi and Wang 2008; Zhou et al. 2008; Chen et al. 2009; Huang and Chan 2012; Huang and Wang 2014; Huang and Chen 2015). Many studies examining the observational data have noted that the summer continental diurnal rainfall generally peaks in the late afternoon (Ramage 1952; Yin et al. 2009; Huang et al. 2010; Huang and Chan 2011), while the oceanic diurnal convection tends to reach its maximum in

\footnotetext{
* Corresponding author

E-mail:wrhuang@ntnu.edu.tw
}

the early morning (Kraus 1963; Andersson 1970). It was suggested that such diurnal rainfall evolution over the continental regions cannot be simulated well by most of the global climate models (Dai 2006; Hara et al. 2009). Because of the computational limitations and the inadequate application of physical processes in resolving the details, simulating the diurnal precipitation variations is one of the many challenging issues in global climate models (Slingo et al. 2004).

Because the horizontal resolution of most global model simulations is generally too coarse to represent the local climate details, the regional climate model has been frequently adopted for dynamical downscaling the global climate simulation results in reproducing the local climate change (e.g., Lin et al. 2015). A general review of how regional climate 
model (i.e., dynamical downscaling) approaches have been investigated and employed over the complex topographic area of Asian region is referred to Hong and Kanamitsu (2014), Lee and Hong (2014), Lee et al. (2014), and Xue et al. (2014). Among these studies, Huang et al. (2013) recently adopted a similar dynamical downscaling approach to obtain more realistic simulations of diurnal precipitation change over South China, and suggested that a regional model setup suitable for diurnal rainfall simulation over South China might not be suitable for simulating diurnal rainfall over other East Asian sub-regions. Huang et al. (2016) used the WRF (Weather Research and Forecasting Model; Skamarock et al. 2008) driven by two super high resolution global climate models and noted that using WRF dynamical downscaling of global model data helped to generate a more realistic diurnal rainfall simulation over Taiwan. However, as inferred from Huang et al. (2013), it is possible that Huang et al.'s (2016) suggested WRF dynamical downscaling approach might not perform well in the simulations of diurnal rainfall variation over South China and Luzon (i.e., the two continental areas closest to Taiwan; marked in Fig. 1).

One of the objectives of this study is to clarify this issue with focus on the performance of WAR-HiRAM [i.e., WRF driven by High Resolution Atmospheric Model (Zhao et al. 2009)] in simulating the diurnal rainfall characteristics over South China and Luzon. It will be shown later that the WRF dynamical downscaling approach suggested by Huang et al. (2016) for simulating Taiwan's diurnal rainfall is also suitable for South China and Luzon's diurnal rainfall simulations. Another objective of this study is to project future changes in summer convective afternoon rainfall (CAR) activity over South China and Luzon. Examinations will be performed to understand what causes the projected changes in CAR activity over South China and Luzon.

The remainder of this study is as follows. In section 2 the model, the observational data and the statistical methods used for the analyses are introduced. Results are presented in section 3 followed by a conclusion given in section 4 . Note, Huang et al. (2016) demonstrated that the WRF-HiRAM's simulation of Taiwan's CAR activity is very similar to those simulated by WRF-MRI [i.e. WRF driven by Meteorological Research Institute Atmospheric General Circulation Model (Mizuta et al.2012)], suggesting the WRF dynamical downscaling approach is not very sensitive to driving forcing. From the preliminarily comparison of WRF-HiRAM (shown later) and WRF-MRI's (not shown) simulated CAR activity, this study also found that the former is very similar to the latter for both South China and Luzon. Therefore, for these simulations we focus only on the results extracted from WRF-HiRAM and its driving forcing (i.e., HiRAM) in this study to make the discussions more concise.

\section{MODELS, OBSERVATIONAL DATA, AND STATISTICAL METHODS}

\subsection{Models}

The dynamical downscaling experiment uses version 3.5.1 of WRF (Skamarock et al. 2008) driven by HiRAM (Zhao et al. 2009). Two time-sliced simulations assuming the climate conditions at present (1979 - 2003, under the historical run) and at the end of the $21^{\text {st }}$ century (2075 - 2099, under the RCP 8.5 scenario) are performed. The HiRAM's horizontal resolution is approximately $25-\mathrm{km}$ over the East Asian summer monsoon region, coupled with 32 vertical layers. Different from HiRAM, the WRF-HiRAM's horizontal resolution is approximately $5-\mathrm{km}$, interval with 36 vertical layers. The simulation domain of WRF-HiRAM covers the areas of $\left(112-130^{\circ} \mathrm{E}, 14.5-32.5^{\circ} \mathrm{N}\right)$ (Fig. 1).

In WRF-HiRAM, the planetary boundary layer simulations use the Noah land surface model (Tewari et al. 2004),

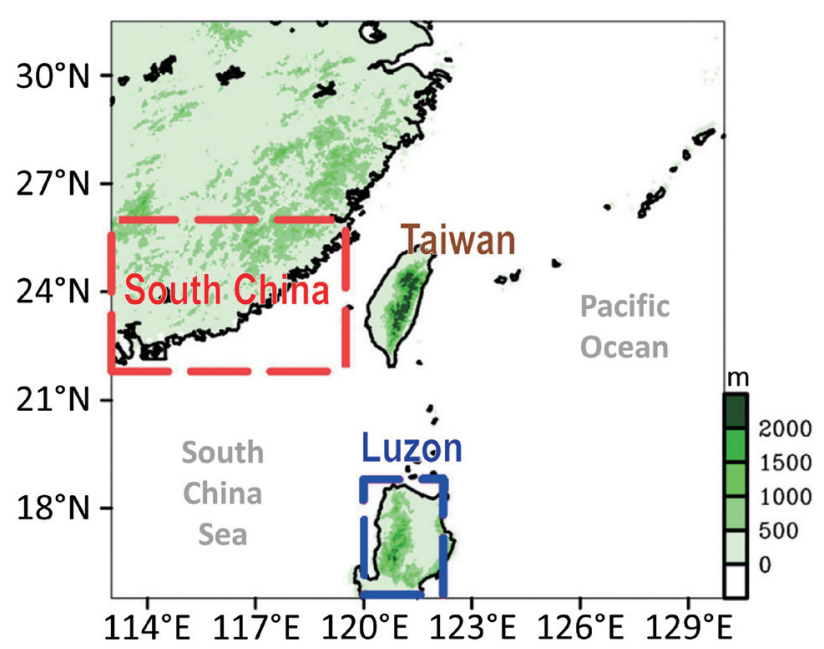

Fig. 1. Topography and geographic location of South China, Luzon, and Taiwan. The South China and Luzon domains are the red and blue boxed areas, respectively. 
the Yonsei-University boundary layer scheme (Hong et al. 2006), and the Monin-Obukhov surface layer scheme (Monin and Obukhov 1954). The microphysics parameterizations use the WRF Single-Moment five-class schemes (Hong et al. 2004). The CAM3 (version 3 of NCAR Community Atmosphere Model) radiation scheme (Collins et al. 2004) is used and the RCP 8.5 GHG concentration is considered in longwave radiation calculation. No cumulus parameterizations are applied. Spectrum nudging is only applied to atmospheric conditions, but not to the boundary layer.

\subsection{Observational Data}

Observed precipitation is derived from 3-hourly TRMM (Tropical Rainfall Measuring Mission) 3B42 satellite precipitation (Huffman et al. 2007). The TRMM 3B42 data provides rain rate at the spatial resolution of $0.25^{\circ}$ longitude $\times 0.25^{\circ}$ latitude, comparable with the common meteorological station network spacing in the East Asian summer monsoon region (Zhou et al. 2008). TRMM 3B42 data has recently been proven to be a good proxy for diurnal convection over the East Asian regions (Hong et al. 2005; Huang and Chan 2011).

\subsection{Statistical Methods}

Based on the diurnal rainfall observational characteristics over South China and Luzon (Fig. 2, to be discussed later), a CAR day is identified as when (1) the accumulated rainfall during 1200 - 2200 LT (local time) is larger than $80 \%$ of the daily rainfall, (2) the accumulated rainfall during $0100-1100$ LT is smaller than $10 \%$ of the daily rainfall, and (3) the days affected by other weather systems (e.g., typhoons) are excluded. These criteria are applied for both the observation and the models. Statistical significances for the analyzed variables are determined using a two-tailed Student's t-test based on the effective degree of freedom (Von Storch and Zwiers 1999). Hereafter, the analyses are presented for LT over South China and Luzon, which are the universal time $+8 \mathrm{~h}$.

\section{RESULTS}

Figure 1 shows the geographical location and the topography of South China, Luzon, and Taiwan. Overall, South China is characterized by lower plains in the south
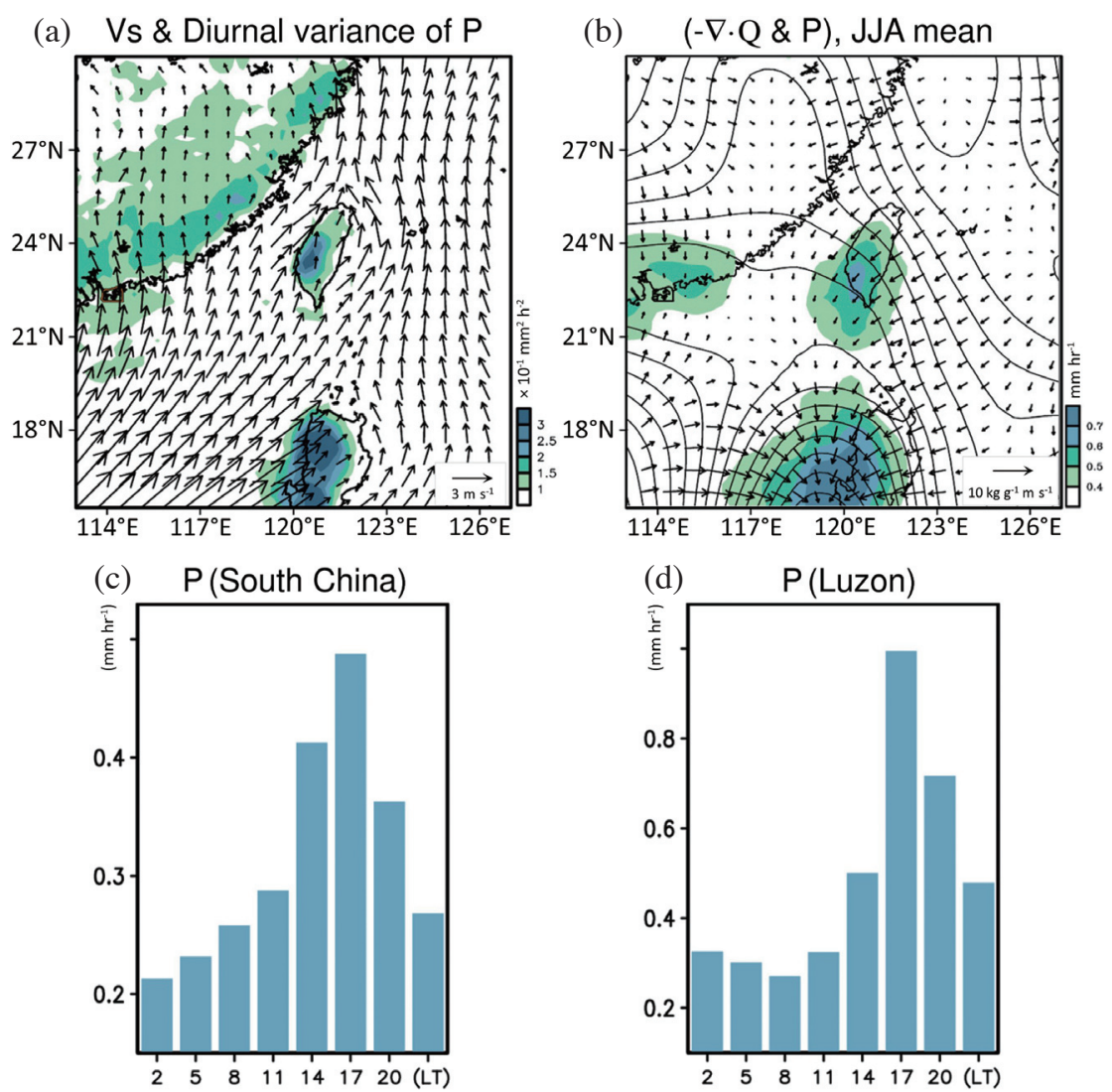

Fig. 2. (a) The diurnal variance of 3-hourly rainfall extracted from TRMM 3B42, superimposed with JJA mean of near-surface wind at $10 \mathrm{~m}$ (i.e., Vs) extracted from MERRA reanalysis during 1998 - 2003 summer seasons. (b) The JJA mean of observational water vapor flux convergence [i.e., $(-\nabla \cdot Q)$; contours] and precipitation (i.e., P; shadings) during the $1998-2003$ summer periods. Here, $(-\nabla \cdot Q)$ is computed based on the following equation: $(-\nabla \cdot \mathrm{Q})=-\nabla \cdot\left(\int^{300 \mathrm{hPa}} \mathrm{Vq} \mathrm{dp}\right)$, where $\mathrm{V}$ denotes the horizontal wind, $\mathrm{q}$ is the specific humidity, and $\mathrm{p}$ is the pressure level. Plots (c) and (d) are the JJA mean 3-hourly rainfall area-averaged over the land areas of South China and Luzon marked in Fig. 1. 
and higher mountains in the north. Luzon is characterized by higher mountains in the west and lower plains in the east. Taiwan is characterized by lower plains in the west and higher mountains in the central-east. The geographic characteristics are obviously very different between South China, Luzon, and Taiwan. It is therefore possible that the model setup suitable for rainfall simulation over Taiwan might not be suitable for rainfall simulation over South China and Luzon. To examine this issue in detail, the discussions in this Section are arranged as follows. Considering that a proper diurnal rainfall simulation is important to a proper CAR activity simulation and projection, we examined the models' capability in simulating the general diurnal rainfall characteristics over South China and Luzon (to be discussed in section 3.1). After that, we then used models to simulate (to be discussed in section 3.2) and project (to be discussed in section 3.3) future change in CAR activity over South China and Luzon.

\subsection{Observed and Simulated Diurnal Rainfall Variations}

Figure 2a shows the spatial distribution of 3-hourly rainfall variations extracted from TRMM 3B42. Visually, note that (except Taiwan) South China and Luzon are the other two regions with larger diurnal rainfall variability. Consistent with previous studies (e.g., Johnson and Bresch 1991), the largest diurnal rainfall variability in Fig. 2a is located at the windward side of the mountains under the modulation of sea breeze convergence, upslope flow and the orographic lifting of prevailing southwesterly flow. It should be noted that although the altitude of highest mountain over Taiwan is higher than the altitude of highest mountain over Luzon, the diurnal rainfall variability in Fig. 2a over Taiwan is smaller than the diurnal rainfall variability over Luzon. This is because compared to Taiwan, Luzon is located in an area where more atmospheric moisture flux convergence appears to support local rainfall formation (Fig. 2b). Regarding how the moisture flux transport can support diurnal rainfall formation over the East Asian region, please refer to Huang et al. $(2010,2013,2015)$.

By examining the temporal variation of 3-hourly rainfall area-averaged over South China (Fig. 2c) and Luzon (Fig. 2d), the results show that both the diurnal rainfall over South China and Luzon tend to reach their maximum at $17 \mathrm{LT}$. This feature is similar to that revealed over Taiwan (Huang et al. 2016). In view of previous studies (e.g., Kikuchi and Wang 2008), one frequently adopted method to illustrate major diurnal rainfall features over a larger domain is to apply an Empirical Orthogonal Function (EOF) analysis on the 3-hourly rainfall. Here, we apply the same EOF analysis to the JJA mean 3-hourly rainfall extracted from TRMM 3B42 over the East Asian domain to summarize the diurnal rainfall characteristics over South China, Luzon, and
Taiwan. The first principal component of the EOF analysis (hereafter, the first EOF mode) is given in Fig. 3.

Note that (1) the largest diurnal rainfall variability generally appeared over South China, Luzon, and Taiwan (see the spatial pattern in Fig. 3), and (2) the observed diurnal rainfall over these three land areas generally peaks at $17 \mathrm{LT}$ (see the temporal pattern in Fig. 3). These findings are consistent with those revealed in Fig. 2, suggesting that most diurnal rainfall characteristics over South China, Luzon, and Taiwan can be well represented by the first EOF mode (which explains about $67.5 \%$ of the total variability in diurnal rainfall; see Fig. 3). Based on this suggestion, the same EOF analysis is applied to the models' simulating JJA mean 3-hourly rainfall (Fig. 4) to help clarify the models' ability to simulate the diurnal rainfall characteristics over the areas of interest.

The results presented in Fig. 4 show that consistent with Fig. 3, both HiRAM and WRF-HiRAM's first EOF modes also explain more than $60 \%$ of the total variability in diurnal rainfall over the analyzed domain. Comparing Fig. 4a with Fig. 3 HiRAM underestimates the diurnal rainfall variability over South China and also has problems in capturing the correct timing of afternoon rainfall maximum over most of the land areas. In contrast, WRF-HiRAM presents a more realistic simulation than HiRAM for the spatial distribution of diurnal rainfall variability (the spatial correlation coefficient between Fig. 4b and Fig. 3 is $\sim 0.8$, while between Fig. $4 \mathrm{a}$ and Fig. 3 is $\sim 0.3$ ). WRF-HiRAM also produces better performance than HiRAM in depicting the diurnal rainfall temporal evolution (temporal correlation coefficient between Fig. 4b and Fig. 3 is $~ 0.95$, while between Fig. $4 \mathrm{a}$ and Fig. 3 is $\sim 0.6$ ) over the analyzed domain.

More evidence supporting that WRF-HiRAM is more capable than HiRAM in simulating diurnal rainfall activity over South China and Luzon can be obtained from a comparison between the observed (Fig. 2) and simulated (Fig. 5) temporal evolution of 3-hourly rainfall area-averaged over South China and Luzon. The results show that HiRAM's simulated diurnal rainfall over South China (Luzon) tends to occur approximately 3 hours earlier (later) than the observed rainfall. These timing shift problems can be corrected after using WRF-HiRAM. Based on these findings (Figs. 2 - 5) it is hypothesized that the WRF dynamical downscaling approach can be applied for a more realistic CAR activity simulation over South China and Luzon. This inference is clarified in the next sub-section.

\subsection{Observed and Simulated CAR Activity}

Figures $6 \mathrm{a}-\mathrm{c}$ show the spatial distribution of CAR amount (i.e., average CAR rainfall accumulated during a summer) estimated by TRMM 3B42, HiRAM, and WRFHiRAM, respectively. The observation (Fig. 6a) shows that larger CAR amount generally occurs over the coastal regions 

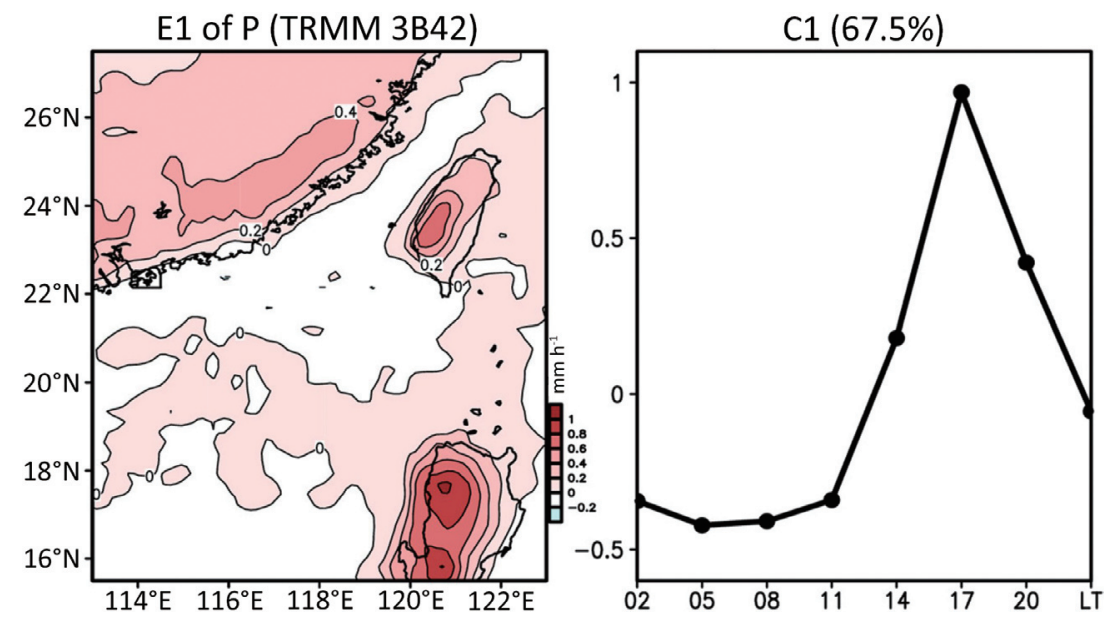

Fig. 3. The Empirical Orthogonal Function (EOF) analysis of JJA mean 3-hourly rainfall extracted from TRMM 3B42. The Eigen-vector of the first principal component (E1) is given in the left panel, and the Eigen-coefficient of the first principal component (C1) is given in the right panel. The percentage $\%$ of the total variability in diurnal rainfall, explained by the first EOF mode is given at the top right.

(a)

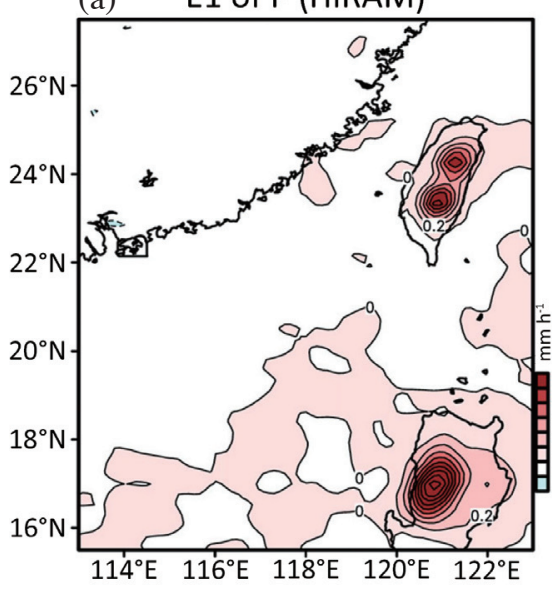

(b) E1 of P (WRF-HiRAM)

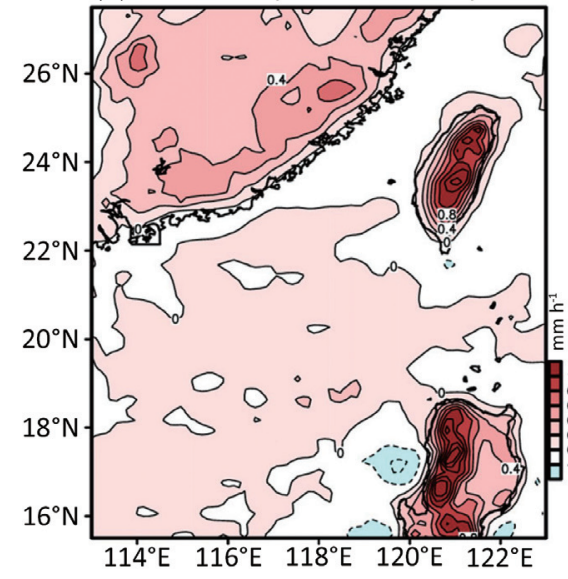

C1 $(61.3 \%)$

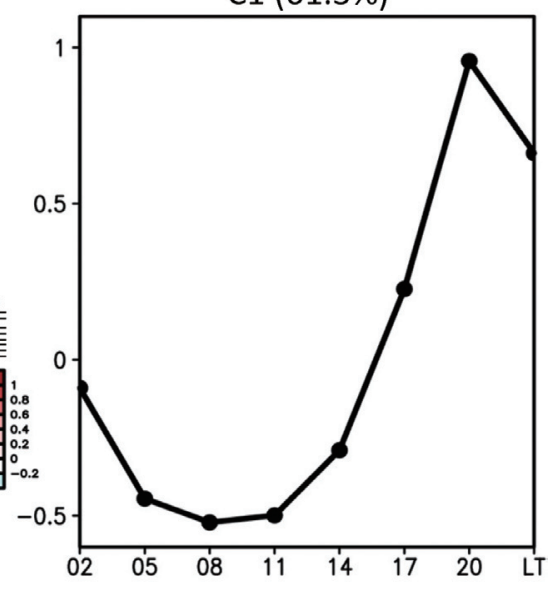

C1 $(69.7 \%)$

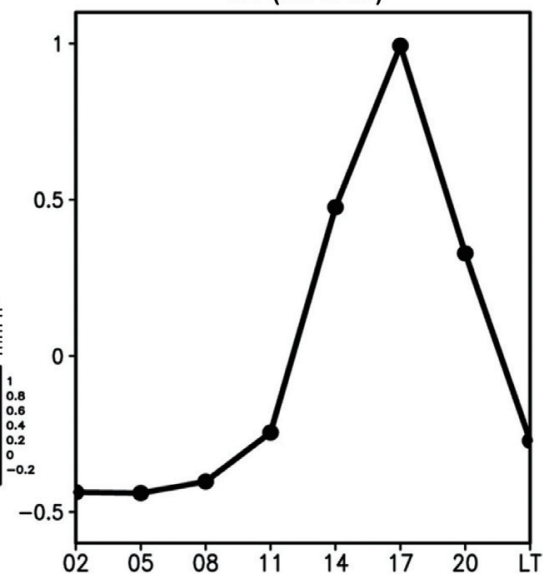

Fig. 4. Similar to Fig. 3, but for the EOF analysis of rainfall extracted from (a) HiRAM and (b) WRF-HiRAM. 
(a) $\mathrm{P}$ (South China)

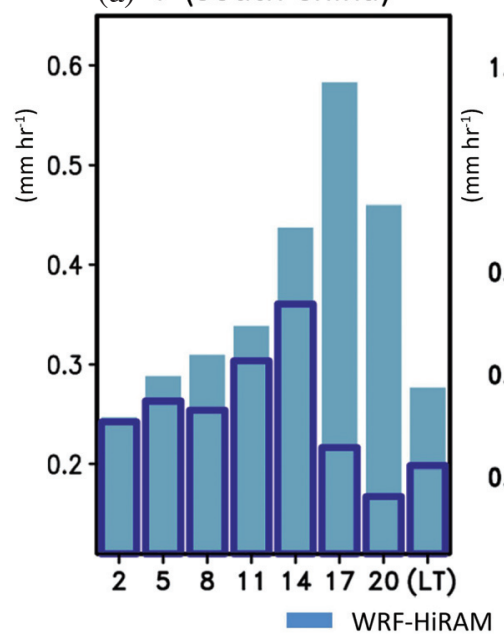

(b) $\quad \mathrm{P}($ Luzon)

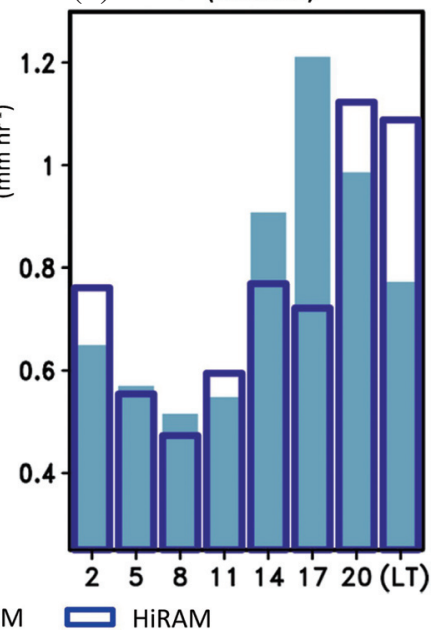

Fig. 5. Plot (a) is similar to Fig. 2c, but for rainfall simulated by HiRAM (outline) and WRF-HiRAM (filled bar) over South China. Plot (b) is similar to plot (a), but for the simulated rainfall over Luzon.
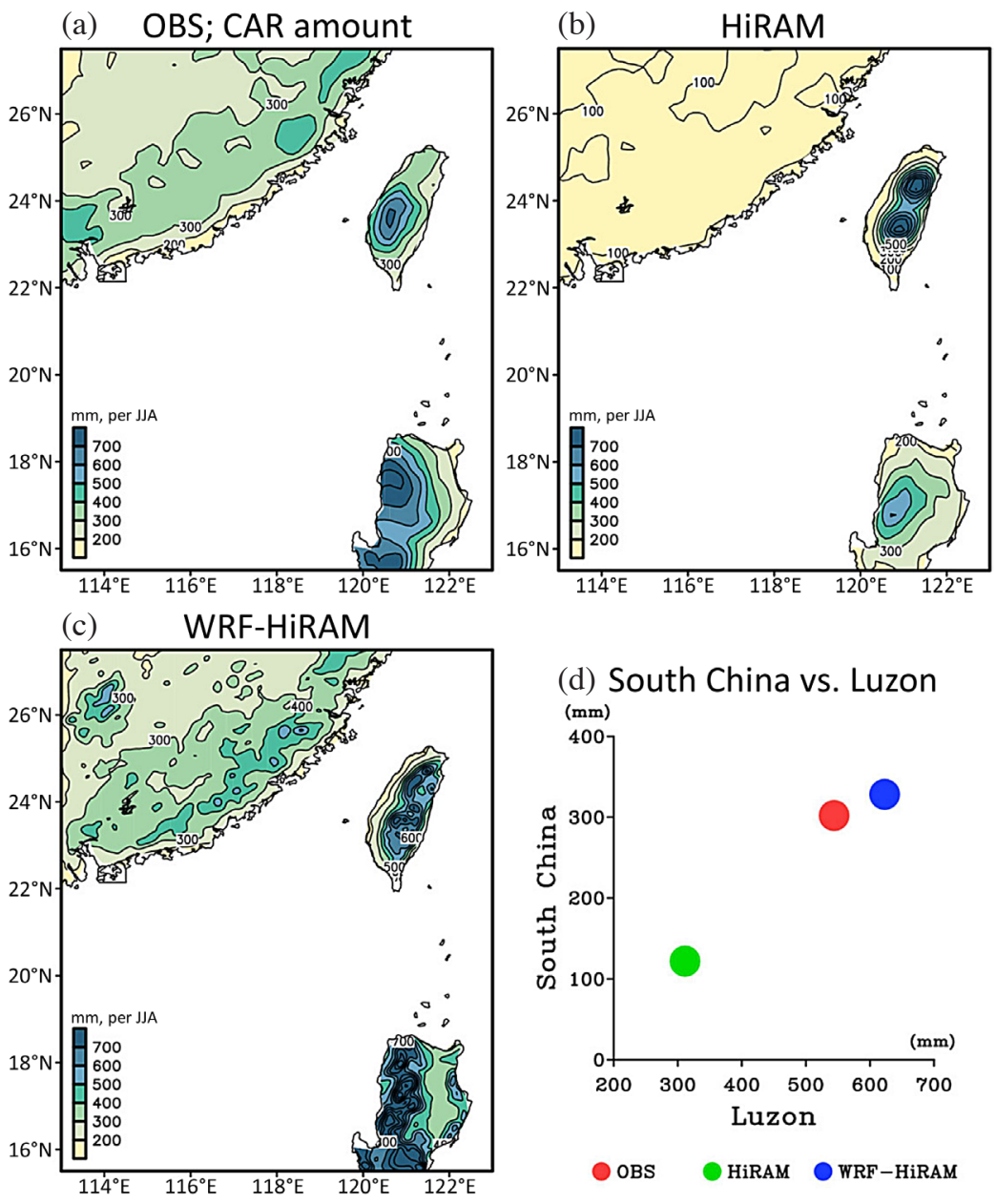

Fig. 6. Summer convective afternoon rainfall (CAR) amount estimated by (a) TRMM 3B42, (b) HiRAM, (c) WRF-HiRAM. The area-averaged of CAR amount over South China and Luzon extracted from (a) - (c) is marked in plot (d). The unit of CAR amount is mm per summer. 
of South China, western Luzon, and western Taiwan. Similar to Fig. 2a, these areas are the windward side of mountains under the prevailing southwesterly monsoon, upslope flow, and sea breeze. Also consistent with Fig. 2a, the CAR amount over western Luzon is larger than that over western South China and western Taiwan. The possible cause for this difference is attributed to that the lower-latitude regions (i.e., Luzon) have more moisture available for rainfall formation, compared to the higher-latitude regions (i.e., Taiwan and South China) (e.g., Huang et al. 2013).

Among these models only WRF-HiRAM (Fig. 6c) is capable of capturing the asymmetric CAR amount pattern over South China (i.e., larger over the coastal regions than over the inner regions). In contrast, both HiRAM and WRFHiRAM are capable of depicting the correct CAR amount distribution over Luzon, with larger values in the west than in the east. To quantitatively evaluate the models' performance in simulating the CAR amount, we computed the observed and simulated CAR amount area-averaged over South China and Luzon. The results are given in Fig. 6d. Notably, HiRAM tends to underestimate the CAR amount not only over South China, but also over Luzon. These biases again can be greatly reduced after using WRF-HiRAM (Fig. 6d).

It is known that the magnitude of CAR amount is determined by the associated change in CAR frequency (i.e., the number of CAR days, per JJA) and CAR rate (i.e., the average rain rate during a CAR day). To further clarify which factor (CAR frequency or CAR rate) contributes most to the HiRAM's bias in underestimating the CAR amount over South China and Luzon, we further evaluated the models' performance in simulating CAR frequency (Fig. 7) and CAR rate (Fig. 8). As seen from the observations (Figs. 7a and 8a), the areas with larger CAR amount (i.e., coastal regions of South China, western Luzon, and western Taiwan) generally consist of larger CAR frequency and larger CAR rate. By comparing these features with those simulated by HiRAM (Figs. $7 \mathrm{~b}$ and $8 \mathrm{~b}$ ), it is noted that over South China HiRAM has a better CAR frequency distribution simulation than CAR rate distribution simulation. In contrast, over Luzon, HiRAM produces better CAR rate distribution simulation than CAR frequency distribution simulation. Quantitatively, HiRAM's simulated CAR frequency and CAR rate over South China are about $15 \%{ }^{1}$ (estimated from Fig. 7d) and 60\% (estimated from Fig. 8d) less than the observed values, respectively. In contrast, over Luzon HiRAM's simulated CAR frequency and CAR rate are about $55 \%$ less (estimated from Fig. 7 d) and $30 \%$ more (estimated from Fig. 8d) than the observed values. These findings imply that HiRAM's problem in underestimating South China's (Luzon's) CAR amount is caused mainly by its errors in simulating CAR rate (CAR frequency).

Note from Figs. 7 - 8, HiRAM's disabilities in simulating the CAR frequency and CAR rate over South China and Luzon can be greatly improved after using WRF-HiRAM. Based on these findings (Figs. 6 - 8), WRF-HiRAM is suggested more capable than HiRAM in simulating the CAR activity over South China and Luzon.

\subsection{Projected Change in CAR Activity}

To project the future changes in CAR, we computed the difference in simulated CAR activity between two selected periods: 2075 - 2099 and 1979 - 2003 (i.e., 2075 2099 minus 1979 - 2003). The results are given in Fig. 9. In South China both HiRAM and WRF-HiRAM predicted that (1) CAR events will become fewer (i.e., decrease in CAR frequency, Figs. 9c - d) but stronger (i.e., increase in CAR rate, Figs. 9e - f) over the entire South China area; and (2) the CAR amount will decrease over the coastal regions, but increase over the inner South China regions (Figs. 9a - b). As inferred from these predictions, future changes in the CAR amount over the inner regions (coastal regions) of South China are most likely contributed by the change in CAR rate (CAR frequency), and contributed less by the change in CAR frequency (CAR rate). Both models also project that CAR over western Luzon will become more frequent and stronger. These changes in CAR activity will lead to an increase in CAR amount over western Luzon. In contrast, for eastern Luzon, a large inter-model difference is found in the projected change in CAR amount (decrease in Fig. 9a, but increase in Fig. 9b). This is attributed to the difference in the projected change in CAR rate (decrease in Fig. 9e, but increase in Fig. 9f), not in the change in CAR frequency (decrease in both Figs. 9c and d).

Examining the change in rain rate, previous observational studies (e.g., Chou et al. 2012) suggested that the change is greatly modulated by the change in atmospheric humidity. As inferred from these studies, it is likely that the projected changes in CAR rate are induced by the projected changes in regional atmospheric humidity. To clarify this inference we examined the differences in simulated atmospheric humidity between 2075 - 2099 and $1979-2003$, at $700 \mathrm{hPa}$ (i.e., the level with clear humidity changes) (Fig. 10). Indeed, both HiRAM and WRF-HiRAM's projections show that (1) the humidity over most of South China and Taiwan will increase in the future; (2) the increase in humidity will be larger over the inner regions than over the coastal regions of South China; and (3) the increase will be larger over western Luzon than over eastern Luzon. By comparing these features with those revealed in Figs. 9e - f, it is noted that most areas with

${ }^{1}$ The estimation is based on an equation: $\left[\frac{(\text { Simulated value - Observed value })}{\text { Observed value }} \times 100 \%\right]$. 

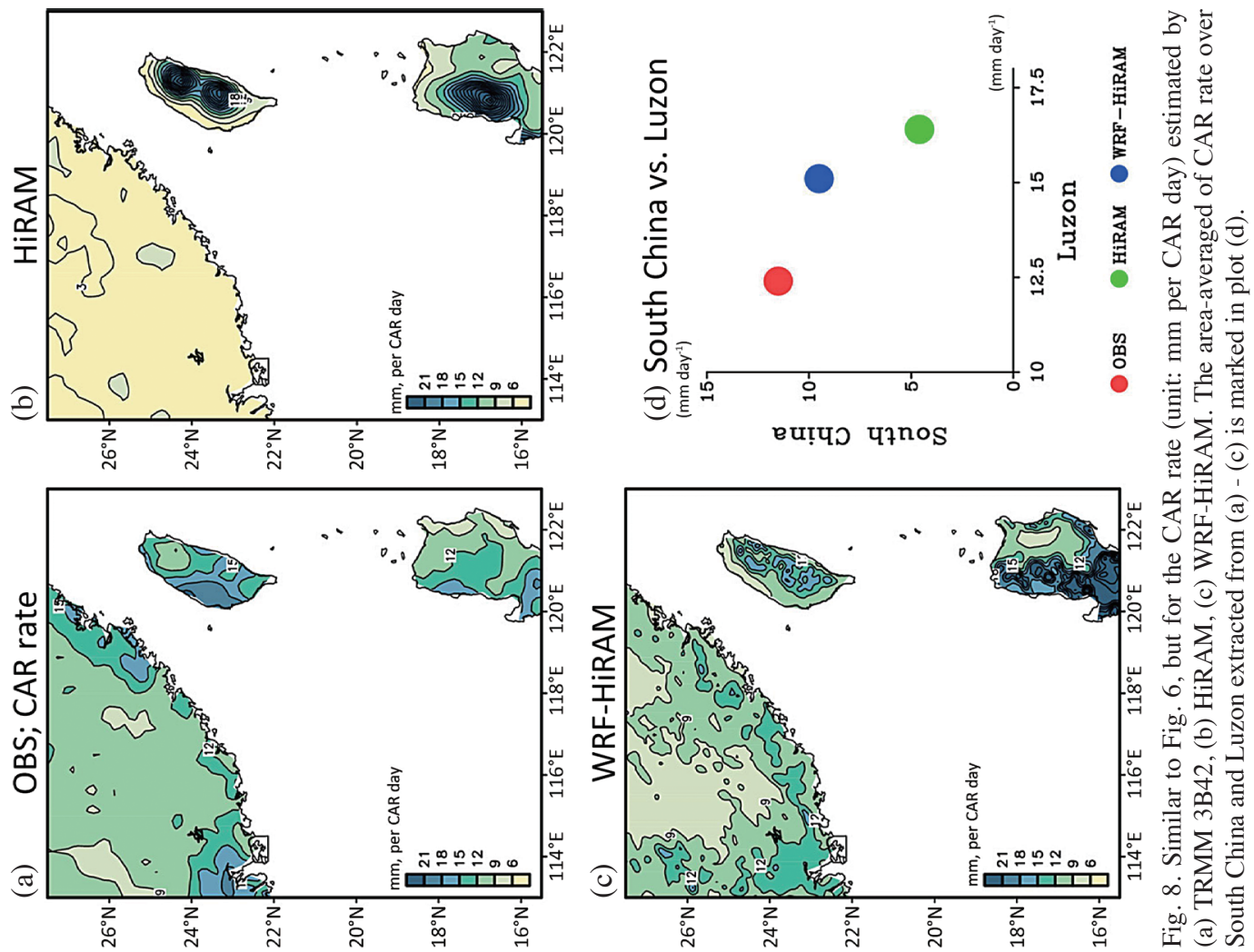

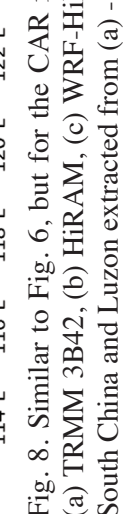
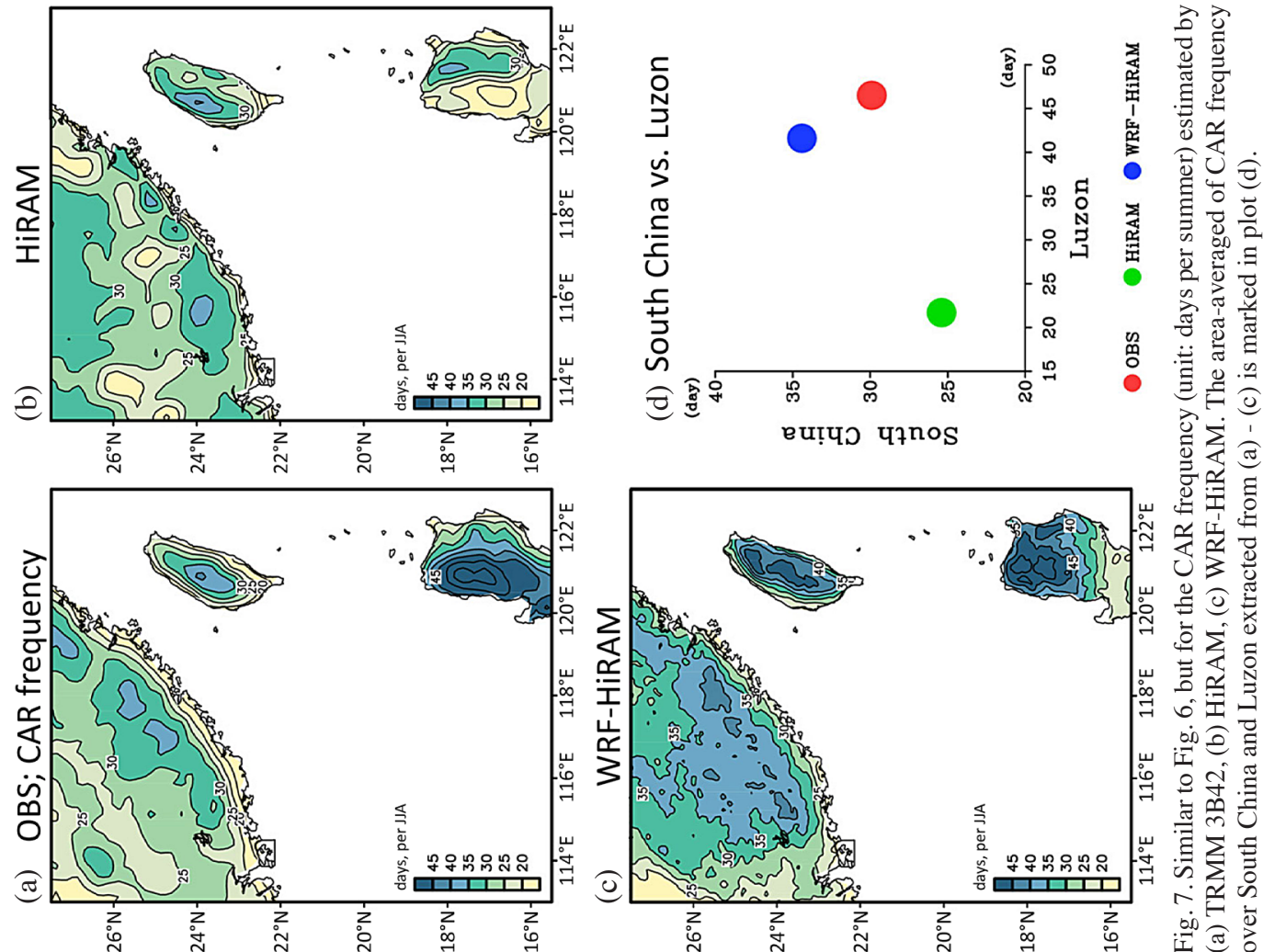
(a) CAR amount; HiRAM

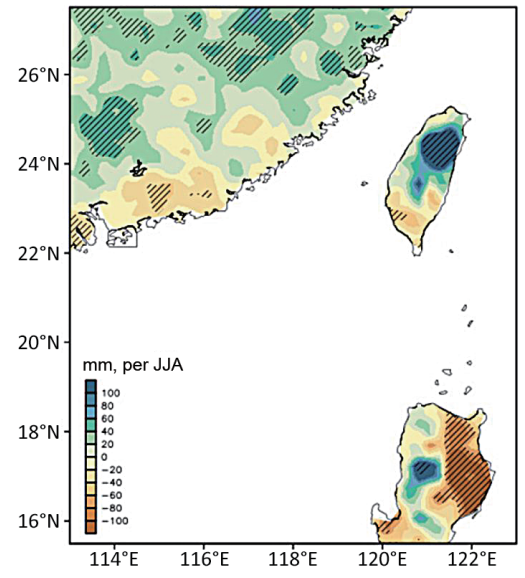

(d) CAR frequency; WRF-HiRAM

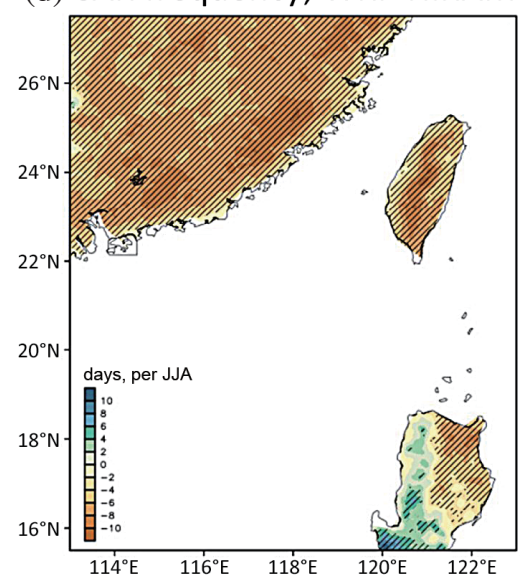

Future-Present

(b) CAR amount; WRF-HiRAM

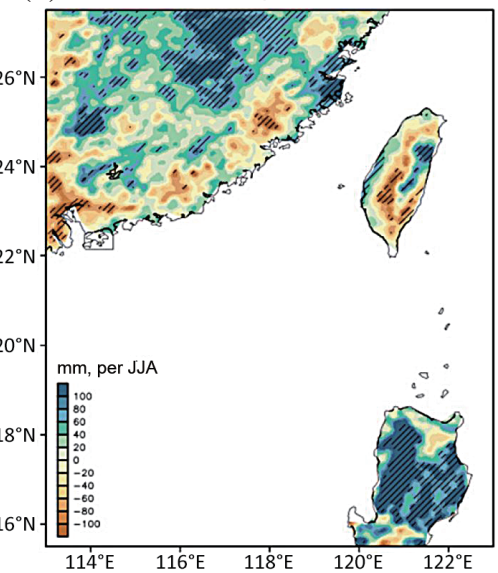

(e) CAR rate; HiRAM

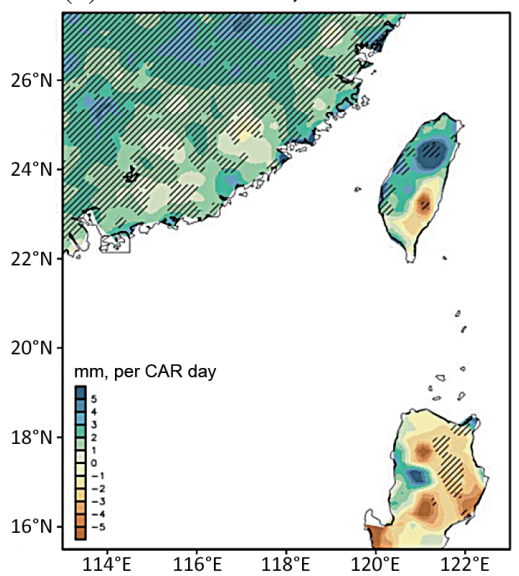

(c) CAR frequency; HiRAM

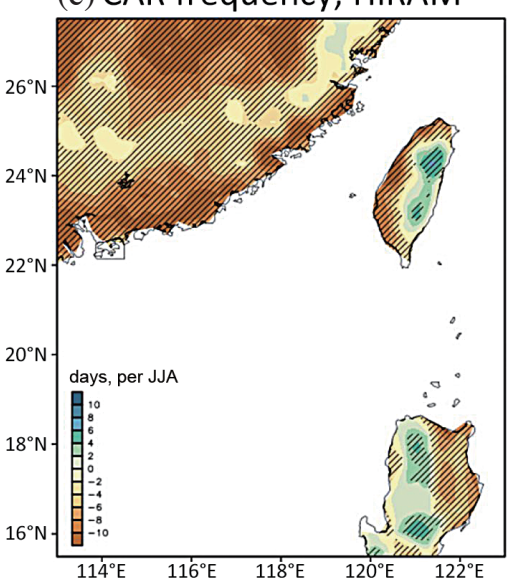

(f) CAR rate; WRF-HiRAM

Fig. 9. Difference between future (2075 - 2099) and present-day (1979 - 2003) simulations of CAR's activity: (a) CAR amount for HiRAM; (b) CAR amount for WRF-HiRAM; (c) CAR frequency for HiRAM; (d) CAR frequency for WRF-HiRAM; (e) CAR rate for HiRAM; (f) CAR rate for

WRF-HiRAM. Only the changes significant at the $90 \%$ confidence interval are marked.
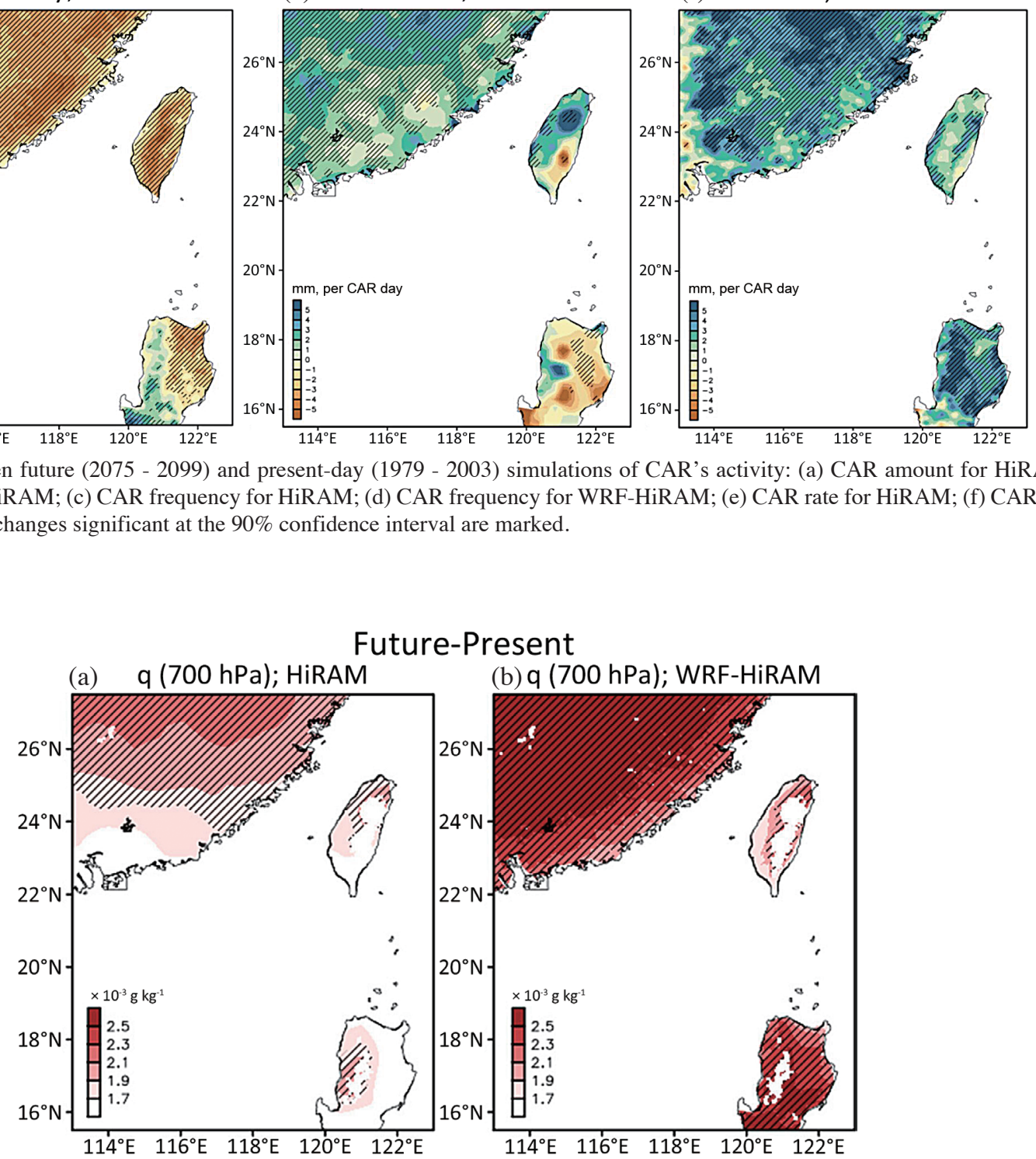

Fig. 10. Difference between future (2075 - 2099) and present-day (1979 - 2003) simulations for atmospheric humidity q at $700 \mathrm{hPa}$. The data are extracted from (a) HiRAM and (b) WRF-HiRAM. Only the changes significant at the $90 \%$ confidence interval are marked. The mountain areas are blocked. 
a significant increase in atmospheric humidity will experience a significant increase in CAR rate. This finding supports our inference that the increase in CAR rate is caused by the increase in atmospheric humidity. As a result of the changes in atmospheric humidity shown in Fig. 10b, WRF-HiRAM projects that the increase in CAR rate over most of Luzon and South China will be larger than the increase in CAR rate over Taiwan (Fig. 9f). Further, it is noted that HiRAM's projected changes in atmospheric humidity over eastern Luzon do not pass the significant test (Fig. 10a). This is different from that revealed in WRF-HiRAM (Fig. 10b). This inter-model difference in projected change in atmospheric humidity may be one of the reasons that explain the different projections in CAR rate change over eastern Luzon.

Finally, we examine what causes the projected changes in CAR frequency over South China and Luzon. In view of part I of this two-part investigation (Huang et al. 2016), it is suggested that the changes in daytime surface wind conver- gence and thermal instability are the two major factors that modulate the changes in CAR frequency over Taiwan. To know if this suggestion can be applied to explain the changes in CAR frequency over South China and Luzon, we examined the projected changes in daytime surface wind convergence (Figs. 11a - b) and thermal instability (Figs. 11c - d), following Huang et al.'s (2016) method. For details of (1) how to deal with horizontal near-surface wind convergence in Figs. 11a - b while the surface winds are not at the same height level (e.g., Luzon), and (2) why the differences in temperature between the surface and $600 \mathrm{hPa}$ were selected for the thermal instability calculation in Figs. $11 \mathrm{c}$ - d, please refer to Huang et al. (2016).

Overall, both HiRAM and WRF-HiRAM predict that daytime surface wind convergence will decrease over most of South China and eastern Luzon, but increase over western Luzon (Figs. 11a - b). These changes in daytime surface wind convergence imply that the dynamic lifting will become

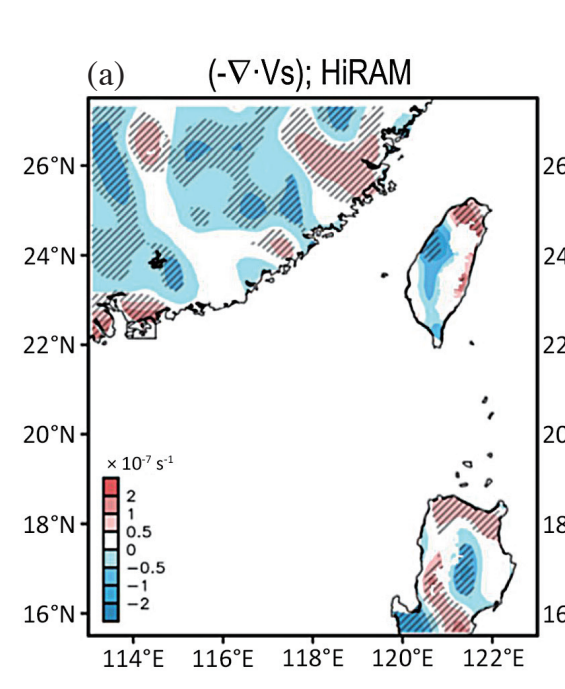

(d) $-\mathrm{dT} / \mathrm{dz}$; WRF-HiRAM

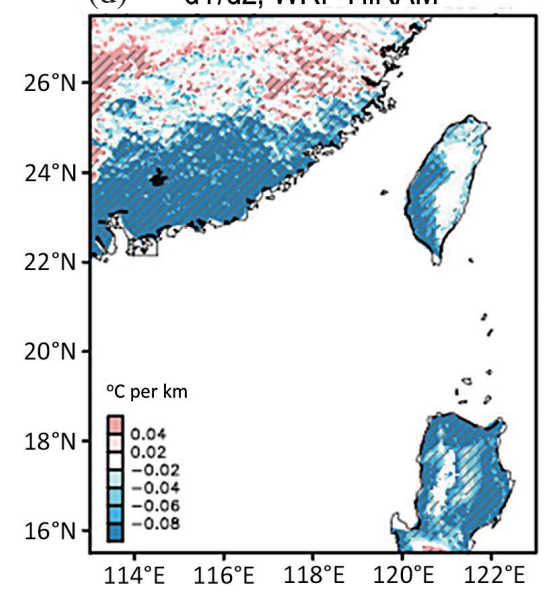

Future-Present (b) $(-\nabla \cdot V s)$; WRF-HiRAM

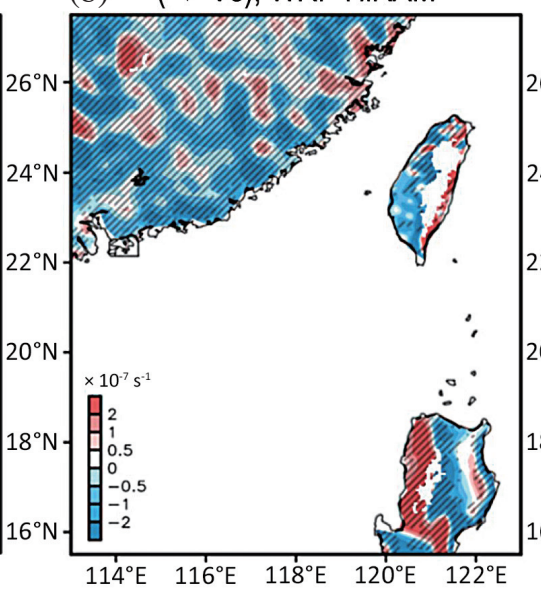

(e) $\mathrm{T} ;$ HiRAM

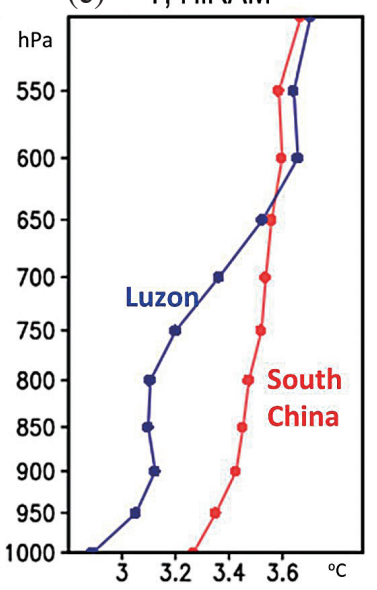

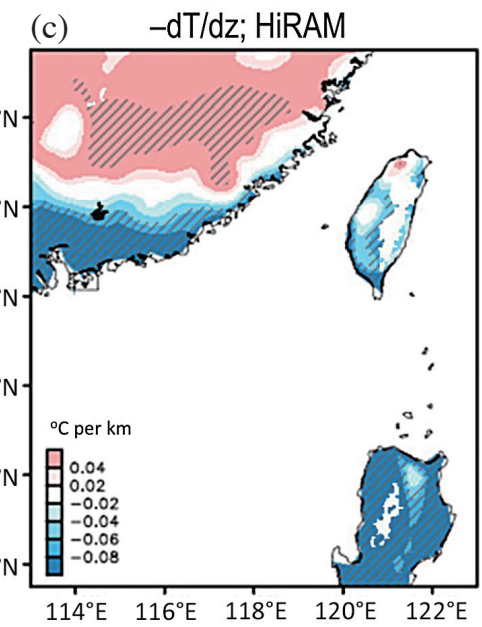

(f) T; WRF-HiRAM

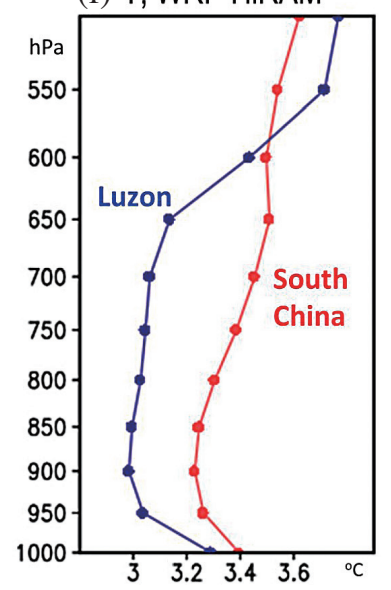

Fig. 11. Difference between future (2075 - 2099) and present-day (1979 - 2003) simulations for (a) - (b) daytime surface wind convergence (- $\nabla \cdot$ Vs) at $14 \mathrm{LT},(\mathrm{c})$ - (d) daytime thermal instability [i.e., -dT/dz (estimated from the temperature change with height, between surface and $600 \mathrm{hPa}$ )] at 14 LT, and (e) - (f) vertical profile of temperature at $14 \mathrm{LT}$ area-averaged over South China and Luzon. The data are extracted from HiRAM and WRFHiRAM. In plots (a) - (d), only the changes significant at the $90 \%$ confidence interval are marked. The mountain areas are blocked. 
weaker (stronger) to suppress (facilitate) the formation of CAR events over most of South China and eastern Luzon (over western Luzon). On the other hand, it can be inferred from Figs. $11 \mathrm{c}-\mathrm{d}$ that the thermal instability will decrease in the future [i.e., $-\mathrm{dT} / \mathrm{dz}$ (future - present) $<0$ ] to suppress CAR event formation over South China and Luzon. Such a decrease in thermal instability over South China and Luzon is induced because the atmospheric warming is predicted to be greater at upper-levels than at low-levels (Figs. 11e - f). This is similar to that predicted over Taiwan (Huang et al. 2016). Altogether, the findings in Fig. 11 suggest that both the change in daytime surface wind convergence and thermal instability should be considered together when explaining the projected change in CAR frequency over South China and Luzon.

Note that in addition to the aforementioned surface wind convergence and thermal instability, the upslope flow and the orographic lifting of prevailing wind (i.e., the topography effect) could be the other two factors important to CAR formation over complex terrain (e.g., Luzon). However, as inferred from Tu et al. (2014), to reasonably discuss the contribution of change in upslope flow and orographic lifting of prevailing flow in affecting CAR formation, more modeling experiments for the topography effect (e.g., with or without topography) are required. Further studies are suggested in the future to clarify the role played by the topography effect on the modulation of future change in CAR activity.

\section{CONCLUSION}

The HiRAM and WRF-HiRAM's performance in simulating and projecting CAR activity over South China and Luzon were examined in this study. The analyses focused on two time-sliced simulations assuming the climate conditions at present $(1979-2003)$ and at the end of the $21^{\text {st }}$ century (2075 - 2099). The present-day simulations showed that WRF-HiRAM produced better performance (compared to HiRAM) in simulating the CAR activity over South China and Luzon. This is attributed to proper simulation of the local diurnal rainfall activity in WRF-HiRAM.

In future projections, both HiRAM and WRF-HiRAM predicted that (1) CAR activity will lessen (i.e., decrease in CAR frequency) but become stronger (i.e., increase in CAR rate) over most of South China; (2) the increase in CAR rate will contribute more (less) than the decrease in CAR frequency over inner (coastal) regions of South China; (3) these changes in CAR rate and CAR frequency will lead to an increase (decrease) in CAR amount over inner (coastal) regions of South China. Additionally, both HiRAM and WRF-HiRAM produced similar projections for future changes in CAR activity over western Luzon. The CAR amount over western Luzon is predicted to increase in the future due to the increase in both CAR frequency and CAR rate. In contrast, larger inter-model differences were found between HiRAM and WRF-HiRAM's projections for the future changes in CAR activity over eastern Luzon. Such different projections for the change in CAR amount (decrease in HiRAM, but increase in WRF-HiRAM) over eastern Luzon were found to be induced because of different projections for the change in CAR rate (decrease in $\mathrm{Hi}$ RAM, but increase in WRF-HiRAM).

Note, the analyses also suggest that the future increase in CAR rate over South China and Luzon is induced because of the increase in atmospheric humidity. It is found that the areas with larger increase in atmospheric humidity (i.e., inner regions of South China and western Luzon) will experience larger increase in CAR rate. On the other hand, the cause of the future decrease in CAR frequency over South China and eastern Luzon is attributed to both the decrease in daytime wind convergence and the decrease in thermal instability. In contrast, for the cause of the future increase in CAR frequency over western Luzon, it is suggested to be induced because of the increase in daytime wind convergence (i.e., dynamic trigger) likely contributing more than the decrease in thermal instability (i.e., thermal trigger).

The characteristics and projected changes in CAR activity over South China and Luzon (documented in this study) are very different from those over Taiwan (documented by Huang et al. 2016). Therefore, it is important and necessary to have this study to clarify the capability of Huang et al.'s (2016) suggested WRF dynamical downscaling approach in simulating CAR activity over South China and Luzon. The results presented in this study can help the local community better understand how regional climate will likely change in the future under global warming. However, it should be mentioned that the results of this study could be dependent on the physical parameterization setup. Further studies on the physical parameterization sensitivity testing with increasing number of vertical levels employed in the models are planned to clarify this issue.

Acknowledgements The authors thank the Anonymous Reviewers for their comments and suggestions which greatly improved this manuscript. This research was supported by the Ministry of Science and Technology of Taiwan under MOST 103-2621-M-865-001, MOST 104-2621-M-865-001, MOST 104-2111-M-003-001, MOST 105-2119-M-003-002, and MOST 105-2625-M-003-002. H. H. Hsu was supported by MOST 100-2119-M-001-029 -MY5, and C. Y. Tu was supported by MOST 105-2111-M-001-001-MY2.

\section{REFERENCES}

Andersson, T., 1970: The diurnal variation of precipitation frequency over Weather Ship M. J. Appl. Meteorol., 9, 17-19, doi: 10.1175/1520-0450(1970)009<0017:TDV $\mathrm{OPF}>2.0 . \mathrm{CO} ; 2$. [Link]

Chen, G., W. Sha, and T. Iwasaki, 2009: Diurnal variation of precipitation over southeastern China: Spatial 
distribution and its seasonality. J. Geophys. Res., 114, D13103, doi: 10.1029/2008JD011103. [Link]

Chou, C., C. A. Chen, P. H. Tan, and K. T. Chen, 2012: Mechanisms for global warming impacts on precipitation frequency and intensity. J. Climate, 25, 32913306, doi: 10.1175/JCLI-D-11-00239.1. [Link]

Collins, W. D., P. J. Rasch, B. A. Boville, J. J. Hack, J. R. McCaa, D. L. Williamson, J. T. Kiehl, B. Briegleb, C. Bitz, S. J. Lin, M. Zhang, and Y. Dai, 2004: Description of the NCAR Community Atmosphere Model (CAM 3.0). NCAR Technical Note NCAR/TN464+STR, National Center for Atmospheric Research, Boulder, Colorado, 214 pp.

Dai, A., 2006: Precipitation characteristics in eighteen coupled climate models. J. Climate, 19, 4605-4630, doi: 10.1175/JCLI3884.1. [Link]

Dai, A., X. Lin, and K. L. Hsu, 2007: The frequency, intensity, and diurnal cycle of precipitation in surface and satellite observations over low- and mid-latitudes. Climate Dyn., 29, 727-744, doi: 10.1007/s00382-0070260-y. [Link]

Hara, M., T. Yoshikane, H. G. Takahashi, F. Kimura, A. Noda, and T. Tokioka, 2009: Assessment of the diurnal cycle of precipitation over the Maritime continent simulated by a $20 \mathrm{~km}$ Mesh GCM using TRMM PR data. J. Meteorol. Soc. Jpn., 87A, 413-424, doi: 10.2151/ jmsj.87A.413. [Link]

Hong, S. Y. and M. Kanamitsu, 2014: Dynamical downscaling: Fundamental issues from an NWP point of view and recommendations. Asia-Pac. J. Atmos. Sci., 50, 83-104, doi: 10.1007/s13143-014-0029-2. [Link]

Hong, S. Y., J. Dudhia, and S. H. Chen, 2004: A revised approach to ice microphysical processes for the bulk parameterization of clouds and precipitation. Mon. Weather Rev., 132, 103-120, doi: 10.1175/1520-0493 (2004)132<0103:ARATIM>2.0.CO;2. [Link]

Hong, S. Y., Y. Noh, and J. Dudhia, 2006: A new vertical diffusion package with an explicit treatment of entrainment processes. Mon. Weather Rev., 134, 2318-2341, doi: 10.1175/MWR3199.1. [Link]

Hong, Y., K. L. Hsu, S. Sorooshian, and X. Gao, 2005: Improved representation of diurnal variability of rainfall retrieved from the Tropical Rainfall Measurement Mission Microwave Imager adjusted Precipitation Estimation From Remotely Sensed Information Using Artificial Neural Networks (PERSIANN) system.J.Geophys. Res., 110, D06102, doi: 10.1029/2004JD005301. [Link]

Huang, W. R. and J. C. L. Chan, 2011: Maintenance mechanisms for the early-morning maximum summer rainfall over southeast China. Q.J.R. Meteorol. Soc., 137, 959-968, doi: 10.1002/qj.815. [Link]

Huang, W. R. and J. C. L. Chan, 2012: Seasonal variation of diurnal and semidiurnal rainfall over Southeast China.
Climate Dyn., 39, 1913-1927, doi: 10.1007/s00382011-1236-5. [Link]

Huang, W. R. and K. C. Chen, 2015: Trends in pre-summer frontal and diurnal rainfall activities during 1982-2012 over Taiwan and Southeast China: Characteristics and possible causes. Int. J. Climatol., 35, 2608-2619, doi: 10.1002/joc.4159. [Link]

Huang, W. R. and S. Y. Wang, 2014: Impact of land-sea breezes at different scales on the diurnal rainfall in Taiwan. Climate Dyn., 43, 1951-1963, doi: 10.1007/ s00382-013-2018-z. [Link]

Huang, W. R., J. C. L. Chan, and S. Y. Wang, 2010: A planetary-scale land-sea breeze circulation in East Asia and the western North Pacific. Q. J.R. Meteorol. Soc., 136, 1543-1553, doi: 10.1002/qj.663. [Link]

Huang, W. R., J. C. L. Chan, and A. Y. M. Au-Yeung, 2013: Regional climate simulations of summer diurnal rainfall variations over East Asia and Southeast China. Climate Dyn., 40, 1625-1642, doi: 10.1007/s00382-0121457-2. [Link]

Huang, W. R., H. H. Hsu, S. Y. Wang, and J. P. Chen, 2015: Impact of atmospheric changes on the low-frequency variations of convective afternoon rainfall activity over Taiwan. J. Geophys. Res., 120, 8743-8758, doi: 10.1002/2015JD023568. [Link]

Huang, W. R., Y. H. Chang, C. T. Cheng, H. H. Hsu, C. Y. Tu, and A. Kitoh, 2016: Summer convective afternoon rainfall simulation and projection using WRF driven by global climate model. Part I: Over Taiwan. Terr. Atmos. Ocean. Sci., 27, 659-671, doi: 10.3319/ TAO.2016.05.02.01. [Link]

Huffman, G. J., R. F. Adler, D. T. Bolvin, G. Gu, E. J. Nelkin, K. P. Bowman, Y. Hong, E. F. Stocker, and D. B. Wolff, 2007: The TRMM Multisatellite Precipitation Analysis (TMPA): Quasi-global, multiyear, combinedsensor precipitation estimates at fine scales. J. Hydrometeorol., 8, 38-55, doi: 10.1175/JHM560.1. [Link]

Johnson, R. H. and J. F. Bresch, 1991: Diagnosed characteristics of precipitation systems over Taiwan during the May-June 1987 TAMEX. Mon. Weather Rev., 119, 2540-2557, doi: 10.1175/1520-0493(1991)119<2540: DCOPSO $>2.0 . C O ; 2$. [Link]

Kikuchi, K. and B. Wang, 2008: Diurnal precipitation regimes in the global tropics. J. Climate, 21, 2680-2696, doi: 10.1175/2007JCLI2051.1. [Link]

Kraus, E. B., 1963: The diurnal precipitation change over the sea. J. Atmos. Sci., 20, 551-556, doi: 10.1175/1520 $-0469(1963) 020<0551:$ TDPCOT $>2.0 . C O ; 2$. [Link]

Lee, J. W. and S. Y. Hong, 2014: Potential for added value to downscaled climate extremes over Korea by increased resolution of a regional climate model. Theor. Appl. Climatol., 117, 667-677, doi: 10.1007/s00704-0131034-6. [Link]

Lee, J. W., S. Y. Hong, E. C. Chang, M. S. Suh, and H. 
S. Kang, 2014: Assessment of future climate change over East Asia due to the RCP scenarios downscaled by GRIMs-RMP. Climate Dyn., 42, 733-747, doi: 10.1007/s00382-013-1841-6. [Link]

Lin, C. Y., Y. J. Chua, Y. F. Sheng, H. H. Hsu, C. T. Cheng, and Y. Y. Lin, 2015: Altitudinal and latitudinal dependence of future warming in Taiwan simulated by WRF nested with ECHAM5/MPIOM. Int. J. Climatol., 35, 1800-1809, doi: 10.1002/joc.4118. [Link]

Mizuta, R., H. Yoshimura, H. Murakami, M. Matsueda, H. Endo, T. Ose, K. Kamiguchi, M. Hosaka, M. Sugi, S. Yukimoto, S. Kusunoki, and A. Kitoh, 2012: Climate simulations using MRI-AGCM3.2 with $20-\mathrm{km}$ grid. J. Meteorol. Soc. Jpn., 90A, 233-258, doi: 10.2151/ jmsj.2012-A12. [Link]

Monin, A. S. and A. M. Obukhov, 1954: Basic laws of turbulent mixing in the surface layer of the atmosphere. Tr. Akad. Nauk SSSR Geophiz. Inst., 24, 163-187.

Ramage, C. S., 1952: Diurnal variation of summer rainfall over east China, Korea and Japan. J. Meteor., 9, 83-86, doi: 10.1175/1520-0469(1952)009<0083:DVOSRO>2 .0.CO;2. [Link]

Skamarock, W. C., J. B. Klemp, J. Dudhia, D. O. Gill, D. M. Barker, M. G. Duda, X. Y. Huang, W. Wang, and J. G. Powers, 2008: A description of the Advanced Research WRF Version 3. NCAR Technical Note NCAR/ TN-475+STR, National Center for Atmospheric Research, Boulder, Colorado, USA, 113 pp, doi: 10.5065/ D68S4MVH. [Link]

Slingo, A., K. I. Hodges, and G. J. Robinson, 2004: Simulation of the diurnal cycle in a climate model and its evaluation using data from Meteosat 7. Q. J. R. Meteorol. Soc., 130, 1449-1467, doi: 10.1256/qj.03.165. [Link]

Tewari, M., F. Chen, W. Wang, J. Dudhia, M. A. LeMone, K. Mitchell, M. Ek, G. Gayno, J. Wegiel, and R. H. Cuenca, 2004: Implementation and verification of the unified NOAH land-surface model in the WRF model. 20th Conference on Weather Analysis and Forecasting/16th Conference on Numerical Weather Prediction, American Meteorological Society, Seattle, WA, US., 6 pp.
Tu, C. C., Y. L. Chen, C. S. Chen, P. L. Lin, and P. H. Lin, 2014: A comparison of two heavy rainfall events during the Terrain-Influenced Monsoon Rainfall Experiment (TiMREX) 2008. Mon. Weather Rev., 142, 24362463, doi: 10.1175/MWR-D-13-00293.1. [Link]

Von Storch, H. and F. W. Zwiers, 1999: Statistical Analysis in Climate Research, Cambridge University Press, 484 pp, doi: 10.1017/CBO9780511612336. [Link]

Xue, Y., Z. Janjic, J. Dudhia, R. Vasic, and F. De Sales, 2014: A review on regional dynamical downscaling in intraseasonal to seasonal simulation/prediction and major factors that affect downscaling ability. Atmos. Res., 147-148, 68-85, doi: 10.1016/j.atmosres.2014.05.001. [Link]

Yin, S., D. Chen, and Y. Xie, 2009: Diurnal variations of precipitation during the warm season over China. Int. J. Climatol., 29, 1154-1170, doi: 10.1002/joc.1758. [Link]

Yu, R., T. Zhou, A. Xiong, Y. Zhu, and J. Li, 2007a: Diurnal variations of summer precipitation over contiguous China. Geophys. Res. Lett., 34, L01704, doi: 10.1029/2006GL028129. [Link]

Yu, R., Y. Xu, T. Zhou, and J. Li, 2007b: Relation between rainfall duration and diurnal variation in the warm season precipitation over central eastern China. Geophys. Res. Lett., 34, L13703, doi: 10.1029/2007GL030315. [Link]

Zhao, M., I. M. Held, S. J. Lin, and G. A. Vecchi, 2009: Simulations of global hurricane climatology, interannual variability, and response to global warming using a 50-km resolution GCM. J. Climate, 22, 6653-6678, doi: 10.1175/2009JCLI3049.1. [Link]

Zhao, Z., L. R. Leung, Y. Qian, 2005: Characteristics of diurnal variations of rainfall in China for the recent years. Exchanges: Newsletter of the Climate Variability and Predictability Programme (CLIVAR), 10, 24-26.

Zhou, T., R. Yu, H. Chen, A. Dai, and Y. Pan, 2008: Summer precipitation frequency, intensity, and diurnal cycle over China: A comparison of satellite data with rain gauge observations. J. Climate, 21, 3997-4010, doi: 10.1175/2008JCLI2028.1. [Link] 